\title{
It ain't closed 'til it's closed
}

\author{
Jihoon Kim, MD, $\mathrm{PhD},{ }^{\mathrm{a}}$ and Jae Won Lee, $\mathrm{MD}, \mathrm{PhD}^{\mathrm{b}}$
}

\footnotetext{
From the ${ }^{\mathrm{a}}$ Department of Thoracic and Cardiovascular Surgery, Kangnam Sacred Heart Hospital, Hallym University Medical Center, Hallym University College of Medicine, and ${ }^{\mathrm{b}}$ Department of Thoracic and Cardiovascular Surgery, Asan Medical Center, University of Ulsan College of Medicine, Seoul, Republic of Korea.

Disclosures: Authors have nothing to disclose with regard to commercial support.

Received for publication May 9, 2017; accepted for publication May 11, 2017; available ahead of print June 27 , 2017.

Address for reprints: Jae Won Lee, MD, PhD, Department of Thoracic and Cardiovascular Surgery, Asan Medical Center, University of Ulsan College of Medicine, 88, Olympic-Ro 43-Gil, Songpa-Gu, Seoul, 05505, Republic of Korea (E-mail: jwlee@amc.seoul.kr).

J Thorac Cardiovasc Surg 2017; 154:849

$0022-5223 / \$ 36.00$

Copyright (C) 2017 Published by Elsevier Inc. on behalf of The American Association for Thoracic Surgery http://dx.doi.org/10.1016/j.jtcvs.2017.05.035
}

A wide range of surgical options are available for exclusion of the left atrial appendage (LAA), including "cutand-sew," stapling, internal suture obliteration, external ligation, and clipping. Leaving technical difficulty aside, it is striking that nearly one-half of LAA exclusion cases fail, despite the apparently simple concept of closing the LAA lumen. ${ }^{1}$ Common types of failure include the residual stump and recanalization. Probable causes of failure include variations in LAA anatomy and the beating nature of the chamber. ${ }^{2}$

In this issue of the Journal, Hui and $\mathrm{Lee}^{3}$ from Saint Louis University present a modified method for performing the internal suture closure of the LAA orifice that has been used in 23 patients at the time of their report. The method adds a so-called "compression stitch," which obliterates the LAA lumen by suturing the internal side of the tip of the LAA to its base after inverting the LAA. By doing so, the potential space of the LAA is "compressed." Then the LAA orifice is closed in the usual manner with double running sutures.

Elimination of the LAA lumen with the compression stitch could decrease the possibility of later recanalization. Another advantage of this technique is that it can be performed in a minimally invasive right thoracotomy approach, including robotic surgery. The relative low cost is another merit of this procedure, which requires only 2 polypropylene sutures and pledgets.

The residual stump remains a problem, however, just as in the classic internal obliteration method when the orifice is closed too far from the left atrial wall. The problem is that surgeons cannot determine this distance when closing the orifice. In addition, the surgeon needs to be able to make the sutures sufficiently tight to prevent later loosening, which can lead to recanalization. Thus, the

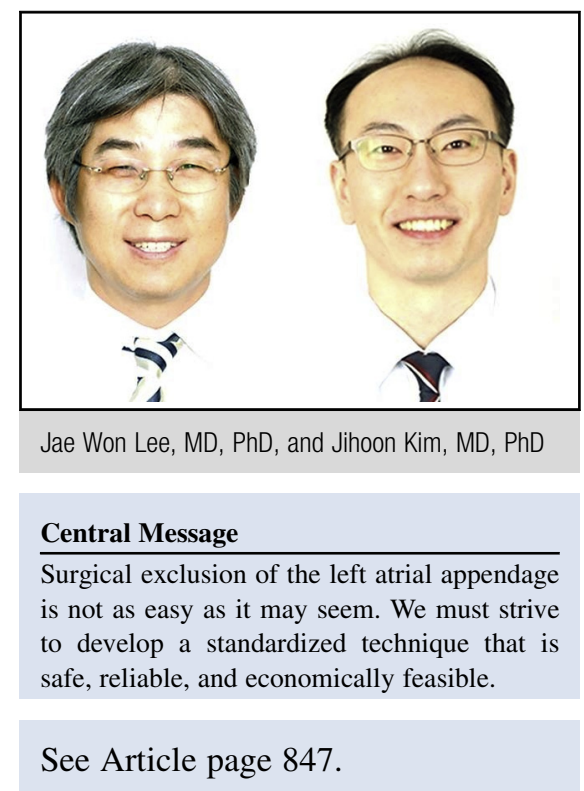

completeness of the LAA exclusion must be carefully evaluated with transesophageal echocardiography by an experienced operator during the procedure. Even after a successful operation, the potential for late recanalization, possibly necessitating medical and/or surgical intervention, should not be overlooked regardless of the duration of follow-up.

Closing the LAA without failure and without complications is a long-held goal, and Hui and Lee should be commended for their efforts toward improving this procedure. Of course, a long-term follow-up study is warranted, and further research is needed to develop a standardized technique for surgical exclusion of the LAA with consistently good results that all surgeons can perform easily at low cost.

\section{References}

1. Lee R, Vassallo P, Kruse J, Malaisrie SC, Rigolin V, Andrei AC, et al. A randomized, prospective pilot comparison of 3 atrial appendage elimination techniques: internal ligation, stapled excision, and surgical excision. J Thorac Cardiovasc Surg. 2016;4:1075-80

2. Lacomis JM, Goitein O, Deible C, Moran PL, Mamone G, Madan S, et al. Dynamic multidimensional imaging of the human left atrial appendage. Europace. 2007;9:1134-40.

3. Hui DS, Lee R. Modified internal ligation of the left atrial appendage. J Thorac Cardiovasc Surg. 2017; 154:847-8. 